Federal Reserve Bank of Minneapolis

Research Department

\title{
Interest Rates and Inflation
}

\author{
Fernando Alvarez, Robert E. Lucas, Jr., \\ and Warren E. Weber* \\ Working Paper 609
}

January 2001

\begin{abstract}
*Alvarez, The University of Chicago; Lucas, The University of Chicago and Federal Reserve Bank of Minneapolis; Weber, Federal Reserve Bank of Minneapolis. We would like to thank Lars Svensson for his discussion, Nurlan Turdaliev for his assistance, and seminar participants at the Federal Reserve Bank of Minneapolis for their comments and suggestions. The views expressed herein are those of the authors and not necessarily those of the Federal Reserve Bank of Minneapolis or the Federal Reserve System.
\end{abstract}




\section{Introduction}

A consensus has emerged about the conduct of monetary policy that now serves as common ground for discussion of the specific policies called for in particular situations. The central elements of this consensus are that the instrument of monetary policy ought to be the short term interest rate, that policy should be focused on the control of inflation, and that inflation can be reduced by increasing short term interest rates.

For monetary economists, participating in discussions where these propositions are taken as given would seem to entail the rejection of the quantity theory of money, the class of theories that imply that inflation rates can be controlled by controlling the rate of growth of the money supply. Such a rejection is a difficult step to take, because the systematic evidence that exists linking monetary policy, inflation, and interest rates - and there is an enormous amount of it - consists almost entirely of evidence that increases in average rates of money growth are associated with equal increases in average inflation rates and in interest rates. Under the quantity theory, rapid money growth is the defining characteristic of monetary ease, and it is associated with high interest rates as well as with high inflation.

Evidence from the postwar period, from the United States and elsewhere, shows that the quantity theory of money continues to provide a reasonable description of the long run average relationships among interest rates, inflation rates, and money growth rates. In particular, the U.S. inflation of the 1970s and 80s can be fully accounted for by the corresponding increase in M2 (or M1) growth rates, and the return to relatively low inflation rates in the 1990s can be explained by the correspondingly low average rate of money supply growth in that decade. Inflation in the 90s was about 3.5 percentage points lower than its average in the $70 \mathrm{~s}$ and $80 \mathrm{~s}$, and the growth rate of M2 was about 5 percentage points lower. The long 
run behavior of interest rates, in the U.S. and elsewhere, can similarly be understood in terms of Fisherian inflation premia. To lose sight of these connections is to lose sight of the one reliable means society has for controlling the long run average inflation rate.

These observations need not rule out a constructive role for the use of short term interest rates as a monetary instrument. One possibility is that increasing short rates in the face of increases in inflation is just an indirect way of reducing money growth: Sell bonds and take money out of the system. Another possibility is that while control of monetary aggregates is the key to low long run average inflation rates, an interest rate policy can improve the short run behavior of interest rates and prices. The short run connections between money growth and inflation and interest rates are very unreliable, so there is much room for improvement. These possibilities are surely worth exploring, but doing so requires new theory: The analysis needed to reconcile interest rate policies with the evidence on which the quantity theory of money is grounded cannot be found in old textbook diagrams.

\section{An Economy with Segmented Markets}

Many theoretical models have been introduced in the last few years, designed to rationalize the use of interest rate policies to control inflation rates. Many of these are centered on a class of policies known as "Taylor rules," rules that specify the interest rate set by the central bank as an increasing function of the inflation rate (or perhaps of a forecast of the inflation rate). ${ }^{1}$ Theories differ considerably in their specification of the economy to which the Taylor rule is assumed to apply.

One class of inflation-targeting models combines an IS-curve, relating the nominal

\footnotetext{
${ }^{1}$ See Taylor (1993).
} 
interest rate to expected inflation (for Fisherian reasons) and production, with a Phillips-like curve relating inflation to production. ${ }^{2}$ Given the interest rate, these two equations can be solved for inflation and production. ${ }^{3}$ These new-Keynesian models have been used to analyze the design of Taylor rules, to determine the forms that would maximize a welfare function that depends on the variability of inflation and real growth rates. But whatever they can tell us about high frequency movements in interest rates and inflation rates, these models contribute nothing to our understanding of why the 60 s and the 90 s were low inflation decades, relative to 70 s and the 80 s, or why Germany has been a low inflation country, relative to Mexico. For these questions, the really important ones from a welfare viewpoint, one needs to rely on some explicit version of the quantity theory of money.

To be useful in thinking about the role of interest rates and open market operations in the control of inflation, a model of monetary equilibrium needs to deal with the fact that most coherent monetary theories do not have anything like a downward sloping demand for nominal bonds: With a complete set of financial markets, it is just not true that when the government buys bonds, the price of bonds increases. We may believe that such a "liquidity effect" occurs in reality (though it is hard to see it in the data) and may regard it as a deficiency that so much of monetary theory ignores it, but the fact remains that one cannot take take a Sidrauski (1967), Brock (1974), or Lucas and Stokey (1987) model off the shelf and use it to think about increases in money reducing interest rates. To engage this liquidity effect it is necessary to adopt a framework in which some agents are excluded from money

\footnotetext{
${ }^{2}$ See Clarida, Gali, and Gertler (1999) for a helpful review.

${ }^{3}$ Where is the LM (which is to say, money demand) curve? It no longer exists, some say, and if it did, we wouldn't have any use for it: Everything we care about has been determined by the two curves already discussed.
} 
markets, at least some of the time. This idea that markets must be segmented, in some sense, for a liquidity effect to occur, is taken from the original work of Grossman and Weiss (1983) and Rotemberg (1984). The particular version of the idea that we use here is adapted from recent papers by Alvarez and Atkeson (1997), Alvarez, Atkeson, and Kehoe (2000) and Occhino (2000),

The model we develop is an exchange economy: There is no Phillips curve and no effect of monetary policy changes on production. Segmented market models that have such effects include contributions by Christiano and Eichenbaum (1992) and Carlstrom and Fuerst (2000). Our simpler model permits a discussion of inflation, but not of all of inflation's possible consequences.

Think, then, of an exchange economy with many agents, all with the preferences

$$
\sum_{t=0}^{\infty}\left(\frac{1}{1+\rho}\right)^{t} U\left(c_{t}\right), \quad \text { where } \quad U\left(c_{t}\right)=\frac{c_{t}^{1-\gamma}}{1-\gamma}
$$

over sequences $\left\{c_{t}\right\}$ of a single, non-storable consumption good. All of these agents attend a goods market every period. A fraction $\lambda$ of agents also attend a bond market. We call these agents "traders." The remaining $1-\lambda$ agents - we call them "non-traders" - never attend the bond market. We assume that no one ever changes status between being a trader and a non-trader.

Agents of both types have the same, constant endowment of $y$ units of the consumption good. The economy's resouce constraint is thus

$$
y=\lambda c_{t}^{T}+(1-\lambda) c_{t}^{N}
$$

where $c_{t}^{T}$ and $c_{t}^{N}$ are the consumptions of the two agent-types. We ensure that money is held in equilibrium by assuming that no one consumes his own endowment. Each household 
consists of a shopper-seller pair, where the seller sells the household's endowment for cash in the goods market, while the shopper uses cash to buy the consumption good from others on the same market. Prior to the opening of this goods market, money and one-period government bonds are traded on a another market, attended only by traders.

Purchases are subject to a cash-in-advance constraint, modified to incorporate shocks to velocity. Assume, to be specific, that goods purchases $P_{t} c_{t}$ are constrained to be less than the sum of cash brought into goods trading by the household, and a variable fraction $v_{t}$ of current period sales receipts. Think of the shopper as visiting the seller's store at some time during the trading day, emptying the cash register, and returning to shop some more.

Thus every non-trader carries his unspent receipts from period $t-1$ sales, $\left(1-v_{t}\right) P_{t+1} y$, into period $t$ trading. He adds to these balances $v_{t} P_{t} y$ from period $t$ sales, giving him a total of $\left(1-v_{t}\right) P_{t+1} y+v_{t} P_{t} y$ to spend on goods in period $t$. In order to keep the determination of the price level as simple as possible, we assume that every household spends all of its cash, every period. ${ }^{4}$ Then every non-trader spends

$$
P_{t} c_{t}^{N}=\left(1-v_{t-1}\right) P_{t-1} y+v_{t} P_{t} y
$$

in period $t$.

Traders, who attend both bond and goods markets, have more options. Like the non-traders, each trader has available the amount on the right of (2) to spend on goods in period $t$, but each trader also absorbs his share of the increase in the per capita money supply that occurs in the open market operation in $t$. If the per capita increase in money

\footnotetext{
${ }^{4}$ After solving for equilibrium prices and quantities under the assumption that cash constraints always bind, one can go back to individual maximum problems to find the set of parameter values under which this provisional assumption will hold. See Alvarez, Atkeson, and Kehoe (2000), Appendix A.
} 
is $M_{t}-M_{t-1}=\mu_{t} M_{t-1}$ then each trader leaves the date $t$ bond market with an additional $\mu_{t} M_{t-1} / \lambda$ dollars. ${ }^{5}$ Consumption spending per trader is thus given by

$$
P_{t} c_{t}^{T}=\left(1-v_{t-1}\right) P_{t-1} y+v_{t} P_{t} y+\left(M_{t}-M_{t-1}\right) / \lambda
$$

Now using the cash flow equations (2) and (3) and the market-clearing condition (1) we obtain

$$
\begin{aligned}
& P_{t} y=\left(1-v_{t-1}\right) P_{t-1} y+v_{t} P_{t} y+M_{t}-M_{t-1} \\
& =M_{t-1}+v_{t} P_{t} y+M_{t}-M_{t-1},
\end{aligned}
$$

since $M_{t-1}=\left(1-v_{t-1}\right) P_{t-1} y$ is total dollars carried forward from $t-1$. Thus a version

$$
M_{t} \frac{1}{1-v_{t}}=P_{t} y
$$

of the equation of exchange must hold in equilibrium, and the fraction $v_{t}$ can be interpreted (approximately) as the $\log$ of velocity.

Introducing shocks to velocity captures the short run instability in the empirical relationship between money and prices. In addition, it allows us to study the way interest rates react to news about inflation for different specifications of monetary policy. In the formulation of the segmented markets model that we use here, there are no possibilities for substituting

\footnotetext{
${ }^{5}$ If $B_{t}$ is the value of bonds maturing at date $t$ and if $T_{t}$ is the value of lump sum tax receipts at $t$, the market clearing condition for this bond market becomes

$$
B_{t}-\left(\frac{1}{1+r_{t}}\right) B_{t+1}-T_{t}=M_{t}-M_{t-1} .
$$

We assume that all taxes are paid by the traders, so Ricardian equivalence will apply and the timing of taxes will be immaterial. These taxes play no role in our discussion, except to give us a second way to change the money supply besides open market operations. With this flexibility, any monetary policy can be made consistent with the real debt remaining bounded. The arithmetic that follows will be both monetarist and pleasant in the sense of Sargent and Wallace (1981).
} 
against cash, so the interest rate does not appear in the money demand function - in (4) — and velocity is simply given. Given the behavior of the money supply, then, prices are entirely determined by (4): This is the quantity theory of money in its very simplest form.

The exogeneity of velocity in the model is, of course, easily relaxed without altering the essentials of the model, but at the cost of complicating the solution method. In the version we study here, the two cash flow equations (2) and (3) describe the way the fixed endowment is distributed to the two consumer types. The three equations (1)-(3) thus completely determine the equilibrium resource allocation and the behavior of the price level. No maximum problem has been studied and no derivatives have been taken!

But to study the related behavior of interest rates, we need to examine bond market equilibrium, and there the real interest rate will depend on the current and expected future consumption of the traders only. Solving (1), (2), and (4), we derive the formula for $c_{t}^{T}$ :

$$
c_{t}^{T}=\left[\frac{1+\mu_{t} v_{t}+\mu_{t}\left(1-v_{t}\right) / \lambda}{1+\mu_{t}}\right] y=c\left(v_{t}, \mu_{t}\right) y,
$$

where the second equality defines the relative consumption function $c\left(v_{t}, \mu_{t}\right)$. Then the equilibrium nominal interest rate must satisfy the familiar marginal condition

$$
\frac{1}{1+r_{t}}=\frac{1}{1+\rho} E_{t}\left[\frac{U^{\prime}\left(c\left(v_{t+1}, \mu_{t+1}\right) y\right)}{U^{\prime}\left(c\left(v_{t}, \mu_{t}\right) y\right)} \frac{1}{1+\mu_{t+1}} \frac{1-v_{t+1}}{1-v_{t}}\right]
$$

where $E_{t}(\cdot)$ means an expectation conditional on events dated $t$ and earlier.

We use two approximations to simplify equation (5). The first involves expanding the function $\log \left(c\left(v_{t}, \mu_{t}\right)\right)$ around the point $(\bar{v}, 0)$ to obtain the first-order approximation

$$
\log \left(c\left(v_{t}, \mu_{t}\right)\right) \cong(1-\bar{v})\left(\frac{1-\lambda}{\lambda}\right) \mu_{t}
$$


(Note that the first-order effect of velocity changes on consumption is zero.) With the CRRA preferences we have assumed, the marginal utility of traders is then approximated by

$$
U^{\prime}\left(c\left(v_{t}, \mu_{t}\right) y\right)=\exp \left(-\phi \mu_{t}\right) y
$$

where

$$
\phi=\gamma(1-\bar{v})\left(\frac{1-\lambda}{\lambda}\right)>0 .
$$

Taking logs of both sides of (5), we have:

$$
r_{t}=\rho-\log \left(E_{t}\left[\exp \left\{-\phi\left(\mu_{t+1}-\mu_{t}\right)\right\} \frac{1}{1+\mu_{t+1}} \frac{1-v_{t+1}}{1-v_{t}}\right]\right) .
$$

We apply a second approximation to the right hand side to obtain

$$
r_{t}=\hat{\rho}+\phi\left(E_{t}\left[\mu_{t+1}\right]-\mu_{t}\right)+E_{t}\left[\mu_{t+1}\right]+E_{t}\left[v_{t+1}\right]-v_{t},
$$

where $\hat{\rho}-\rho>0$ is a risk correction factor. ${ }^{6}$

From equation (6) one can see that the immediate effects of an open market operation bond purchase, $\mu_{t}>0$, is to reduce interest rates by $\phi \mu_{t}$. This is the liquidity effect that the segmented market models are designed to capture. If we drop the segmentation and let everyone trade in bonds, then $\lambda=1, \phi=0$, and the liquidity effect vanishes. In this case, open market operations can only affect interest rates through information effects on the

\footnotetext{
${ }^{6}$ In fact, $\hat{\rho}-\rho=\frac{1}{2} \operatorname{Var}_{t}\left(z_{t}\right)$,

where

$$
z_{t}=-\phi\left(\mu_{t+1}-\mu_{t}\right)-\mu_{t+1}-v_{t+1}+v_{t} .
$$

In the applications of (9) that we consider below, $\operatorname{Var}_{t}\left(z_{t}\right)$ will not vary with $t$ under a given monetary policy rule, though it will vary with changes in the policy rule.
} 
inflation premium. Interest rate increases can only reflect expected inflation: monetary ease.

With $\phi>0$, the model combines quantity-theoretic predictions for the long run behavior of money growth, inflation, and interest rates, with a potential role for interest rates as an instrument of inflation control in the short run. We explore this potential in the next section.

\section{Inflation Control with Segmented Markets}

In this section, we work through a series of thought experiments based on the equilibrium condition (6) that illuminate various aspects of monetary policy. These examples all draw on the fact, obtained by differencing the equation of exchange (4), that the inflation rate is the sum of the money growth rate and the rate of change in velocity:

$$
\pi_{t}=\mu_{t}+v_{t}-v_{t-1} .
$$

Example 1: (Constant velocity and money growth.) Let $v_{t}$ be constant at $\bar{v}$ and $\mu_{t}$ be constant at $\mu$, Then (6) becomes

$$
r=\rho+\mu .
$$

We can view this equation interchangeably as fixing money growth, given the interest rate, or as fixing the interest rate given money growth and inflation. This Fisher equation must always characterize the long run average money growth, inflation, and interest rates.

Example 2: (Constant money growth and iid shocks.) Let the velocity shocks be iid random variables, with mean $\bar{v}$ and variance $\sigma_{v}^{2}$. Let $\mu_{t}$ be constant at $\mu$. Under these conditions, (6) implies

$$
r_{t}=\widehat{\rho}+\mu-\left(v_{t}-\bar{v}\right) .
$$


A transient increase in velocity raises the current price level, reducing expected inflation. This induces a transient decrease in interest rates. In this example, $r_{t}$ is iid, with mean $\widehat{\rho}+\mu$ and variance $\sigma_{v}^{2}$; the inflation rate has mean $\mu$ and variance $2 \sigma_{v}^{2}$.

Example 3: (Exact inflation targeting.) It is always possible to attain a target inflation rate $\bar{\pi}$ exactly. Just set the money growth rate according to

$$
\mu_{t}=\bar{\pi}-v_{t}+v_{t-1}
$$

Then interest rates will be given by

$$
r_{t}=\hat{\rho}+\phi\left(-E_{t}\left[v_{t+1}\right]+2 v_{t}-v_{t-1}\right)+\bar{\pi} .
$$

If the velocity shocks are iid, as in the Example 2, then $\operatorname{Var}\left(\mu_{t}\right)=2 \sigma_{v}^{2}$, and $r_{t}$ has mean $\widehat{\rho}+\bar{\pi}$ and variance $5 \phi^{2} \sigma_{v}^{2}$.

Example 4: (An interest rate peg.) Assume iid $v_{t}$, with mean $\bar{v}$ and variance $\sigma_{v}^{2}$. Let $\mu_{t}$ satisfy

$$
\mu_{t}-\mu=B\left(v_{t}-\bar{v}\right)
$$

where the constant $B$ is chosen to make $r_{t}$ constant at $\widehat{\rho}+\mu$. Then (6) implies

$$
\widehat{\rho}+\mu=\widehat{\rho}-B \phi\left(v_{t}-\bar{v}\right)+\mu-\left(v_{t}-\bar{v}\right) .
$$

If this equality holds for all realizations of $v_{t}$, it follows that $B=-1 / \phi$. In this case, $\operatorname{Var}\left(\mu_{t}\right)=$ $\left(\sigma_{v} / \phi\right)^{2}$. The variance of the inflation rate is, using (7),

$$
\sigma_{\pi}^{2}=\operatorname{Var}\left(\mu_{t+1}+v_{t+1}-v_{t}\right)=\left[1+\left(\frac{\phi-1}{\phi}\right)^{2}\right] \sigma_{v}^{2}
$$


Comparing this case to Example 2, one sees that pegging the interest rate is inflationstabilizing, relative to constant money growth, if and only if

$\phi>1 / 2$.

In Examples 2, 3, and 4, the economy is subjected to unavoidable velocity shocks. The variability of these shocks must show up somewhere, either in interest rates, money growth rates, or inflation rates. The way it is distributed over these three variables can, in the presence of a liquidity effect, be determined by policy. However this is done, the long run connections between money growth, inflation, and interest rates are entirely quantitytheoretic.

Our next four examples consider versions of Taylor rules. Suppose, to be specific, that interest rates are set according to the formula

$$
r_{t}=\widehat{\rho}+\bar{\pi}+\theta\left(\pi_{t}-\bar{\pi}\right)
$$

where $\theta>0$ means that if the current inflation rate $\pi_{t}$ is to exceed the target rate $\bar{\pi}$, we raise this period's interest rate above its target level, $\widehat{\rho}+\bar{\pi}$. To study the dynamics implied by the rule (8), we eliminate $r_{t}$ and $\pi_{t}$ between (6), (7), and (8) to obtain the difference equation

$$
\mu_{t}-\bar{\pi}=\frac{1+\phi}{\theta+\phi}\left(E_{t}\left[\mu_{t+1}\right]-\bar{\pi}\right)+\frac{1}{\theta+\phi}\left[E_{t}\left[v_{t+1}\right]-v_{t}-\theta\left(v_{t}-v_{t-1}\right)\right]
$$

We can solve this difference equation "forward" to get

$$
\mu_{t}-\bar{\pi}=\sum_{i=0}^{\infty}\left(\frac{1+\phi}{\theta+\phi}\right)^{i} E_{t}\left[s_{t+i}\right]
$$

where

$$
s_{t}=\frac{1}{\theta+\phi}\left[v_{t+1}-v_{t}-\theta\left(v_{t}-v_{t-1}\right)\right]
$$


provided that the series on the right of (10) converges. $^{7}$ We now use (10) to study three more examples.

Example 5: (A Taylor rule with iid velocity). Let $v_{t}$ be iid, with mean $\bar{v}$ and variance $\sigma_{v}^{2}$. Then for any $t$,

$$
\begin{aligned}
& E_{t}\left[s_{t}\right]=\frac{1}{\theta+\phi}\left[\bar{v}-v_{t}-\theta\left(v_{t}-v_{t-1}\right)\right], \\
& E_{t}\left[s_{t+1}\right]=\frac{1}{\theta+\phi}\left[-\theta\left(\bar{v}-v_{t}\right)\right],
\end{aligned}
$$

and $E_{t}\left[s_{t+j}\right]=0$ for $j \geq 2$. Inserting these values into (10) gives

$$
\mu_{t}-\bar{\pi}=-\frac{\phi+\theta^{2}}{(\theta+\phi)^{2}}\left(v_{t}-\bar{v}\right)+\frac{\theta}{\theta+\phi}\left(v_{t-1}-\bar{v}\right) .
$$

The interest rate consequences of these open market operations can then be calculated from the Taylor rule, (8):

$$
r_{t}=\widehat{\rho}+\bar{\pi}+\frac{\theta \phi}{(\theta+\phi)^{2}}(2 \theta+\phi-1)\left(v_{t}-\bar{v}\right)-\frac{\theta \phi}{\theta+\phi}\left(v_{t-1}-\bar{v}\right) .
$$

The money supply response to a temporary increase in velocity, described in (11), is to reduce money growth initially, increase it in the next period, and return to the target growth rate thereafter. This will smooth the inflationary impact of the velocity increase, whether or not there is a positive liquidity effect $\phi$. If $\phi>0$ and $2 \theta+\phi>1$, (12) implies that these open market operations will raise the interest rate initially in response to a velocity increase, then reduce it below the target, and then return it to $\widehat{\rho}+\bar{\pi}$.

\footnotetext{
${ }^{7}$ If $\theta>1$, the right side of (10) is the only solution to (9) with bounded expected values. This case is referred to as an "active" Taylor rule. If $\theta<1$ (a "passive" Taylor rule) and the series in (10) converges, (10) gives one solution to (9) but there will be others - which we do not examine here - as well.
} 
Example 6: (A Taylor rule with serially correlated velocity.) Assume that $v_{t}-\bar{v}$ has mean 0 and variance $\sigma_{v}^{2}$, and follows an autoregression with parameter $\delta \in(-1,1)$ :

$$
E_{t}\left[v_{t+k}-\bar{v}\right]=\delta^{k}\left(v_{t}-\bar{v}\right)
$$

Then for any $t$, calculating the terms $E_{t}\left[s_{t+k}\right]$ and substituting into (10) yields

$$
\mu_{t}-\bar{\pi}=A\left(v_{t}-\bar{v}\right)-\frac{\theta}{\theta+\phi}\left(v_{t-1}-\bar{v}\right)
$$

where the constant $A$ is given by

$$
A=\frac{1}{\theta+\phi}(\delta-1-\theta)+\frac{1}{\theta+\phi}\left[\delta^{2}-(1+\theta) \delta+\theta\right] \sum_{k=1}^{\infty}\left(\frac{1+\phi}{\theta+\phi}\right)^{k} \delta^{k-1} .
$$

Of course, this solution presupposes that the series on the right converges. A sufficient condition for convergence is

$$
\delta<\frac{\theta+\phi}{1+\phi}
$$

Again, the interest rate consequences can be calculated from the Taylor rule, (8):

$$
r_{t}=\widehat{\rho}+\bar{\pi}+\theta(1+A)\left(v_{t}-\bar{v}\right)-\theta\left[\frac{\theta}{\theta+\phi}+1\right]\left(v_{t-1}-\bar{v}\right)
$$

Notice, too, that with $\delta=1$ we get $\delta^{2}-(1+\theta) \delta+\theta=0$, and the constant $A$ is equal to $-\theta /(\theta+\phi)$. In this case, interest rates follow

$$
r_{t}=\widehat{\rho}+\bar{\pi}+\frac{\theta \phi}{\theta+\phi}\left(v_{t}-\bar{v}\right)-\theta\left[\frac{\theta}{\theta+\phi}+1\right]\left(v_{t-1}-\bar{v}\right)
$$

As in the case of iid shocks in Example 5, (13) implies that open market bond sales in response to a velocity increase will increase interest rates only if $\phi>0$.

Example 7: (A change in the inflation target.) Holding the distribution of velocity shocks fixed, suppose the inflation target is moved permanently from $\bar{\pi}$ to $\hat{\pi}$. This re-targeting 
changes nothing on the right side of (10), so (10) implies simply an immediate, permanent change in the money growth rate from $\bar{\pi}$ to $\hat{\pi}$. Of course, this implies an immediate, permanent change in the interest rate of $\hat{\pi}-\bar{\pi}$. Neither the size $\phi$ of the liquidity effect nor the responsiveness $\theta$ of the Taylor rule has any bearing on these changes.

Example 8: (A Taylor rule on the expected inflation rate.) Our final example considers a variation on the Taylor rule, proposed by Svensson (1999), in which an expected, future inflation rate is targeted. That is, we replace (8) with

$$
r_{t}=\hat{\rho}+\bar{\pi}+\theta\left(E_{t}\left[\pi_{t+1}\right]-\bar{\pi}\right)
$$

Provided that $\phi>0$, we can combine (14) with (6) and (7) to obtain a difference equation in $\mu_{t}-\bar{\pi}$ :

$$
\mu_{t}-\bar{\pi}=\frac{1+\phi-\theta}{\phi} E_{t}\left[\mu_{t+1}-\bar{\pi}\right]+\frac{1-\theta}{\phi}\left(E_{t}\left[v_{t+1}\right]-v_{t}\right)
$$

The derivation is the analogue to the derivation of (9) for the contemporaneous Taylor rule. For the case of iid shocks, the stationary solution to (15) is

$$
\mu_{t}-\bar{\pi}=-\left(\frac{1-\theta}{\phi}\right)\left(v_{t}-\bar{v}\right)
$$

Substituting back into (14), we find the corresponding solution for the interest rate:

$$
r_{t}=\hat{\rho}+\bar{\pi}-\theta\left(v_{t}-\bar{v}\right)
$$

Note that in constrast Example 5, a temporary velocity increase leads in this case to a reduction in the the interest rate. The variance of the inflation rate under such a policy is

$$
\sigma_{\pi}^{2}=\left[1+\left(\frac{1-\phi-\theta}{\phi}\right)^{2}\right] \sigma_{v}^{2}
$$

The Taylor rule on the expected inflation rate that minimizes the inflation variance has the coefficient $\theta=1-\phi$. 


\section{Conclusions}

Can a policy of increasing short term interest rates to reduce inflation be rationalized with essentially quantity-theoretic models of monetary equilibrium? Based on an analysis using a model of segmented markets, we give this question a qualified affirmative answer. In the model we used to generate all of our specific examples, production is a given constant, velocity is an exogenous random shock, and the equation of exchange determines the equilibrium price level, given the money supply. In this theory of inflation, consistent with much of the evidence, interest rates play no role whatsoever.

To this simple model we have added segmented markets: Only a fraction of the agents in the economy participate in the money market in which open market operations take place. This segmentation produces a liquidity effect: The nominal interest rate becomes a decreasing function of the rate of money growth. With this added feature, we can describe a monetary policy action interchangeably as a change in the money supply or as a change in interest rates. In this context, we considered a series of examples under different assumptions on the behavior of velocity shocks and on the specification of a policy rule.

In the first two stochastic examples, Examples 2 and 3, a policy at any date is set in advance of the realization of the velocity shock in that period: One can commit to a given rate of money growth, leaving interest rates free to vary with the velocity shock (Example 2 ), or one can commit to an interest rate, leaving money growth to be adjusted later to maintain this rate (Example 3). Neither policy can reduce the variance of inflation to zero. The larger is the liquidity effect, the higher is the relative effectiveness of the interest rate rule in stabilizing inflation rates about a target rate.

In the remaining examples we consider, policy (however specified) is permitted to 
respond to contemporaneous velocity shocks. In Example 4, we show that under this assumption an inflation target can be hit exactly by a money supply rule that is conditioned on the shock, and that this is true whatever is the shock process. In our context, inflation targeting cannot be done any better than this.

The remaining examples in the paper consider Taylor rules: policies in which the interest rate is set so as to deviate from its long run (Fisherian) target in proportion to the deviation of the inflation rate from its target. Such rules use the same information as the rule in Example 4 that attains the inflation target perfectly. From the view point of inflation targeting, then, committing to a Taylor rule amounts to tying the hands of the monetary authority in a way that can only limit its effectiveness. As our examples illustrate, the importance of this limitation varies with assumptions on the time series character of the velocity shocks.

To rationalize the use of any of the interest rate rules we have examined, then, it would be necessary to use an objective function that assigns weight to some other objective besides the attainment of an inflation target. We have in fact considered variations on the model presented here in which relative endowments of agents fluctuate, giving rise to gains from pooling endowment risk. In a model with segmented markets where such pooling cannot take place, there can be real gains from policies that smooth real interest rates. We leave the analysis of this question, the issue of what the founders of the Federal Reserve System called an "elastic currency," to another paper. 


\section{References}

Alvarez, Fernando and Andrew Atkeson. 1997. "Money and Exchange Rates in the GrossmanWeiss-Rotemberg Model." Journal of Monetary Economics, 40: 619-640.

Alvarez, Fernando, Andrew Atkeson, and Patrick Kehoe. 2000. "Money, Interest Rates, and Exchange Rates with Endogenously Segmented Asset Markets." Federal Reserve Bank of Minneapolis working paper.

Brock, William A. 1974. "Money and Growth: The Case of Long-Run Perfect Foresight." International Economic Review, 15: 750-777.

Carlstrom, Charles T., and Timothy S. Fuerst. 2000. "Forward-Looking Versus BackwardLooking Taylor Rules." Federal Reserve Bank of Cleveland working paper.

Christiano, Larence J., and Martin Eichenbaum. 1992. "Liquidity Effects and the Monetary Transmission Mechanism." American Economic Review, 82: 346-353.

Clarida, Richard, Jordi Gali, and Mark Gertler. 1999. "The Science of Monetary Policy: A New Keynesian Perspective." Journal of Economic Literature, 37: 1661-1707.

Grossman, Sanford J., and Laurence Weiss. 1983. "A Transactions-Based Model of the Monetary Transmission Mechanism." American Economic Review, 73: 871-880.

Lucas, Robert E., Jr. and Nancy L. Stokey. 1987. "Money and Interest in a Cash-in-Advance Economy." Econometrica, 55: 491-513.

McCallum, Bennett T. 1988. "Robustness Properties of a Rule for Monetary Policy." CarnegieRochester Conference Series on Public Policy, 29: 173-203.

Occhino, Filippo. 2000. "Heterogeneous Investment Behavior and the Persistence of the Liquidity Effect." University of Chicago doctoral dissertation. 
Rotemberg, Julio J. 1984. "A Monetary Equilibrium Model with Transactions Costs." Journal of Political Economy, 92: 40-58.

Sargent, Thomas J., and Neil Wallace. 1981. "Some Unpleasant Monetarist Arithmetic." Federal Reserve Bank of Minneapolis Quarterly Review.

Sidrauski, Miguel. 1967. "Rational Choice and Patterns of Growth in a Monetary Economy." American Economic Review, 57: 534-544.

Svensson, Lars E.O. 1999. "Inflation Targeting as a Monetary Policy Rule." Journal of Monetary Economics, 43: 607-654.

Taylor, John B. 1993. "Discretion Versus Policy Rules in Practice." Carnegie-Rochester Conference Series on Public Policy, 39: 195-214. 